\title{
A GESTÃO DE TI E O VALOR DE USO DOS ERP'S EM SUA PERSPECTIVA DE PÓS IMPLEMENTAÇÃO
}

\section{1- Cesar Augusto Biancolino*}

Doutor em Contabilidade pela Universidade de São Paulo (USP), Brasil.

Professor do Programa de Mestrado Profissional em Administração da Universidade Nove de Julho (PMPA/UNINOVE), Brasil.

biancolino@gmail.com

http://lattes.cnpq.br/4701779533683744

\section{2- Emerson Antonio Maccari}

Doutor em Administração pela Universidade de São Paulo (USP), Brasil.

Coordenador do Programa de Mestrado Profissional em Administração da Universidade Nove de Julho (PMPA/UNINOVE), Brasil.

emersonmaccari@gmail.com

http://lattes.cnpq.br/1320281388219996

\section{3- Claudia Terezinha Kniess}

Doutor em Ciência e Engenharia de Materiais pela Universidade Federal de Santa Catarina (UFSC), Brasil

Professor do Programa de Mestrado Profissional em Administração da Universidade Nove de Julho (PMPA/UNINOVE), Brasil.

kniesscl@yahoo.com.br

http://lattes.cnpq.br/8233265633962510

\section{4- Giovane da Costa}

Mestrando em Administração pela Universidade Nove de Julho (PMPA/UNINOVE), Brasil.

giovanedc@gmail.com

http://lattes.cnpq.br/0408626104807345

\footnotetext{
* Contato Principal: Universidade Nove de Julho, Programa de Mestrado e Doutorado em Administração - PMD. Avenida Francisco Matarazzo, 612. Água Branca, São Paulo - SP, Brasil. CEP: 05001-100.
} 


\section{A GESTÃO DE TI E O VALOR DE USO DOS ERP'S EM SUA PERSPECTIVA DE PÓS IMPLEMENTAÇÃO}

\section{RESUMO}

Esta pesquisa tem como principal objetivo identificar um conjunto de competências organizacionais inerentes à área da gestão de Tecnologia da Informação - TI em organizações que estejam diretamente relacionadas à gestão do ERP em sua fase de pós-implementação, inferindo em seu valor de uso notado pelas principais áreas destas organizações que são usuárias deste tipo de aplicativo. Para alcançar tal objetivo, este estudo está estruturado em um referencial teórico associado tanto à literatura voltada para o estudo das competências organizacionais voltadas para a área de TI referenciando-se em Saga e Zmud (1994), Boudreau (2003), Mizik e Jacobson (2003) e Clark, Jones, Zmud (2006) como também em um referencial teórico voltado para o estudo da gestão dos sistemas ERP's em sua perspectiva de principal ator da suíte de aplicativos associados à Tecnologia da Informação Empresarial, a partir da análise dos trabalhos de Mata, Fuerst, Barney (1995), Bharadwaj (2000), Li, Chen, Huang (2006) e Souza e Zwicker (2007). A pesquisa foi realizada junto a cinco grandes empresas usuárias de aplicativos ERP's com faturamento anual acima de 1 bilhão de reais, todas pertencentes a diferentes segmentos do cenário econômico brasileiro. A metodologia utilizada previu o desenvolvimento do método de estudo de casos múltiplos, baseado nas obras de Yin (2005) e Martins (2006). Os resultados sugerem que a área de Tl é, de fato, a área responsável pela manutenção e/ou aumento do valor de uso dos sistemas ERP em sua perspectiva de longo prazo. Identificou-se ainda que as demais áreas das organizações não se reconhecem como co-responsáveis pela gestão do sistema ERP, justamente por não terem maior aderência a este conjunto específico de competências ora descrito.

\section{Palavras-Chave}

ERP, Tecnologia da Informação, Sistemas de Informação.

\section{IT MANAGEMENT AND VALUE OF USE OF ERP IN THEIR PERSPECTIVE POST IMPLEMENTATION}

\section{ABSTRACT}

This research aims to identify a set of organizational competencies inherent in the management field of Information Technology - IT in the companies that are directly related to the management of their ERP postimplementation phase, inferring its value in use by major areas noted those organizations which are members of this type of application. To achieve this goal, this study is structured into a theoretical literature associated with both dedicated to the study of organizational skills geared towards IT field referencing in Saga and Zmud (1994), Boudreau (2003), Mizik and Jacobson (2003) and Clark, Jones, Zmud (2006) as well as in a theoretical framework aimed to study the management of ERP's in your perspective as the main actor in the suite of applications associated with the Information Technology Enterprise, from the analysis of work Mata, Fuerst, Barney (1995), Bharadwaj (2000), Li Chen, Huang(2006) and Souza and Zwicker (2007). The research was conducted with five major companies using ERP applications with annual revenues exceeding one billion dollars, all belonging to different segments of the Brazilian economy. The methodology predicted the development of the method of multiple case study, based on the work of Yin (2005) and Martins (2006). The results suggest that IT is, in fact, the area responsible for maintaining and / or increase the value of use of ERP systems in its long-term perspective. It was also found that other areas of the organizations do not recognize themselves as co-managing the ERP system, exactly because they have greater adherence to this particular set of skills described herein.

\section{Keywords}

ERP, Information Technology, Information Systems. 


\section{Introdução}

Inseridos na dinâmica da gestão da Tecnologia da Informação (TI), ainda que os investimentos nesta área representem valores significativos dos aportados pelas empresas em suas operações, os recorrentes questionamentos de natureza gerencial acerca do retorno sobre o investimento em TI são tão legítimos quanto inevitáveis. Conforme Laurindo (2006, p. 167) “Ao mesmo tempo em que surge a pressão pela justificativa dos investimentos, surge também a dificuldade de avaliá-los, pois o contexto da aplicação dos recursos de $\mathrm{TI}$ também mudou e os aplicativos estão sendo utilizados de forma mais complexa e sofisticada."

Neste sentido, a problemática da mensuração do valor da TI no âmbito empresarial tem-se apresentado muito mais complexa quando tecnologias específicas têm sido analisadas nas suas múltiplas dimensões e em diferentes momentos de sua evolução histórica. O Enterprise Resource Planning System - ERP - é um dos representantes destas tecnologias. Este tipo de aplicativo não só é complexo em sua própria constituição tecnológica como também causa inúmeros impactos em vários processos de negócio das organizações, de diferentes maneiras e em diferentes momentos da cadeia informacional.

A mudança da natureza do valor dos benefícios gerados pelos ERP's com o passar do tempo, fato este associado à sua constante evolução (provocadas pelo surgimento de novas versões, novas funcionalidades e novas tecnologias), fazem com que os sistemas ERP sejam precursores de contínuas mudanças no formato de gestão dos processos de negócios das empresas. A medida em que o valor dos ERP's tende a se dissipar com o tempo devido não só às próprias mudanças notadas nos ERP's mas também impulsionados por frequentes mudanças nos ambientes interno e externo das organizações que fazem uso dos aplicativos ERP's para aquisição e manutenção de vantagens competitivas associadas à inovação.

Ainda no mesmo contexto, de acordo com a perspectiva temporal associada à fase de pósimplementação dos ERP's, o valor de uso destes aplicativos dependerá, dentre outros fatores, das capacidades (capabilities) ou competências organizacionais associadas à criação de valor e à apropriação do valor envolvidas nesta etapa do ciclo de vida do ERP. Para Mizik e Jacobson (2003), o processo de criação de valor em uma organização envolve a identificação de recursos e capacidades organizacionais internas que possam contribuir para este objetivo, entretanto, para que o valor criado pela conjunção de recursos e capacidades organizacionais seja preservado no decorrer do tempo, é preciso que a organização aproprie-se deste valor antes que os seus competidores o façam. De acordo com Mizik e Jacobson (2003, p.63):

As empresas se deparam com a tarefa estratégica de equilibrar os dois processos (de criação de valor e de apropriação de valor) em suas estratégias e determinar como se dará o suporte para cada um deles. As empresas necessitam de forma simultânea desenvolver ou adquirir capacidades relacionadas à criação de valor que facilitem a apropriação de valor. Estes dois conjuntos de capacidades requerem investimentos financeiros substanciais e atenção permanente da gerência.

Nota-se pelas afirmações de Mizik e Jacobson (2003) que os processos de construção e de apropriação (sustentação) do valor em uma organização são aderentes à visão de Davenport et al (2002), no sentido que a dinamicidade da utilização dos aplicativos ERP's gera valores de diferentes naturezas no decorrer do tempo, o que sugere que as competências organizacionais relacionadas à dinamicidade de uso e de gestão dos aplicativos ERP's tenham influência significativa neste processo.

Utilizando-se deste conjunto de considerações, o valor de uso dos aplicativos ERP's pode se analisado a partir de três dimensões principais, a saber: (a) à complexidade dos aplicativos ERP's, de acordo com a sua constituição tecnológica e abrangência operacional, (b) o fator temporal associado a cada evento capaz de criar valor e à respectiva análise de valor associada e (c) à necessidade de se estabelecer um conjunto de competências organizacionais que sejam capazes não só de possibilitar a geração de valor a partir do uso de aplicativos ERP's, mas que também possibilite a organização apropriar-se deste valor de forma efetiva e duradoura.

\section{Problemática, Questão Principal e Objetivos da Pesquisa}

Com base nestes fatos, observa-se que a gestão da Tecnologia da Informação em uma organização, por estar intimamente vinculada à gestão dos aplicativos ERP em sua fase de pós implementação, passa a estar cercada por uma problemática vinculada às competências organizacionais inerentes a este processo; em outras palavras, pode-se contextualizar o problema de pesquisa na forma pela qual a área de TI 
corporativa identifica, reúne e realiza a gestão de competências necessárias para maximizar o retorno sobre o investimento e o valor de uso dos sistemas ERP, em sua perspectiva de longo prazo.

Neste contexto, o tema "pós-implementação continuada" ou "manutenção da vantagem competitiva sustentável" ligado ao valor de uso dos ERP's nas organizações ainda é um assunto muito pouco pesquisado e consequentemente associado a poucas referências bibliográficas diretas. Desta forma, a dificuldade de se identificar quais são as competências organizacionais da área de TI que de fato agregam valor ao sistema ERP, é um problema recorrente. Diante desta problemática, a questão principal de pesquisa deste estudo é: Qual o papel das competências organizacionais da área de TI das organizações que estão vinculadas ao processo de sustentação do valor de uso do ERP?

Para responder a esta questão, a pesquisa tem como objetivo principal identificar um conjunto de competências organizacionais inerentes à área de TI das organizações que estejam diretamente relacionadas à gestão do ERP em sua fase de pós implementação, inferindo positivamente em seu valor de uso notado pelas principais áreas usuárias destas organizações.

\section{Fundamentação Teórica}

Segundo Boudreau (2003) a qualidade do uso do sistema ERP refere-se a como a organização explora as capacidades do sistema ERP. Este autor afirma que softwares complexos, como os sistemas ERP trazem embutidos diversas características e funcionalidades que podem ser exploradas das mais variadas formas pelos usuários do sistema, já que nem todas as organizações implementam todos os módulos de um ERP ao mesmo tempo e nem as implementações são feitas da mesma maneira em todas as organizações (Umble, Haft, Umble, 2003).

De acordo com esta visão, Clark, Jones, Zmud (2006) destacam que os usuários de empresas que utilizam o sistema ERP tendem a apresentar diversos modos de utilizar o sistema, apresentando padrões distintos de interação com o aplicativo. Desta forma, a qualidade do uso do sistema ERP tende a variar de forma significativa não somente entre as organizações como também no interior da própria organização. Neste aspecto, Boudreau (2003), identifica duas dimensões de uso do sistema ERP, classificando-as como limitada, quando os usuários utilizam-se apenas das funcionalidades básicas e não exploratórias da ferramenta e extensiva, quando os usuários utilizam-se da maioria das funcionalidades da ferramenta com liberdade para explorar todos os recursos oferecidos pelo ERP. Neste mesmo estudo, Boudreau (2003) identifica a subutilização do sistema ERP na fase de pós implementação como o principal inibidor da geração de benefícios que podem ser proporcionados pelo sistema. Ratificando as pesquisas de Boudreau (2003), Clark et al. (2006, p.21) reforçam esta visão, afirmando que:

Estes exemplos [ das pesquisas realizadas por Boudreau] esclarecem a complexidade das estruturas de autoavaliação inerentes à evolução das percepções e comportamentos característicos da fase de pós-adoção [ do ERP] e reforça o reconhecimento que não existem soluções simples ou únicas a serem seguidas de modo a alcançar de forma apropriada os benefícios decorrentes da implementação de um sistema ERP.

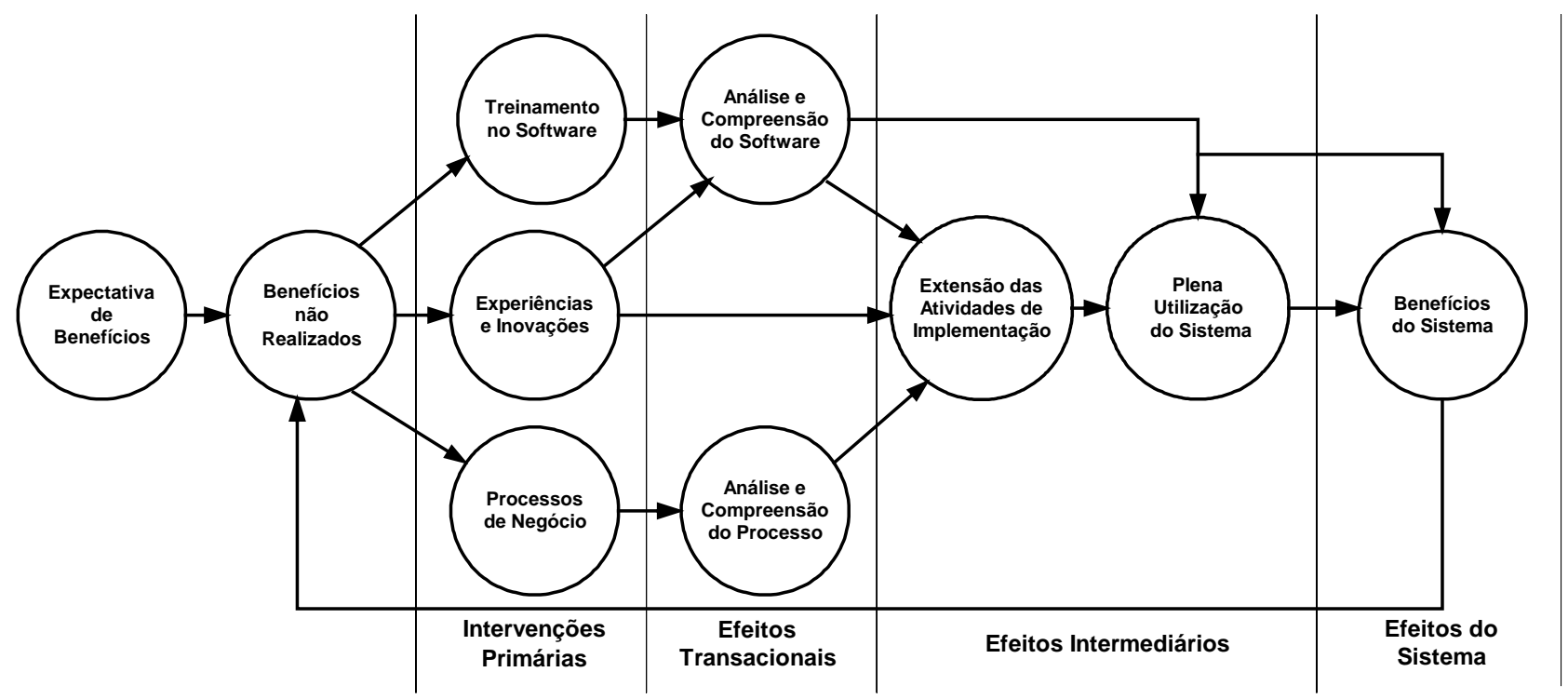

Figura 1 - Modelo conceitual de auto-regulação em termos da obtenção do valor de uso do ERP.

FONTE: Adaptado de Clark et. al., 2006, p.5. 
Segundo Clark et al. (2006), as organizações que possuem como meta atingir todos os benefícios advindos do ERP devem adotar mecanismos de aperfeiçoamentos constantes em sua cadeia de aprendizado interno, de acordo com modelos internos de melhorias contínuas, de forma a retroalimentar constantemente uma determinada cadeia informacional que seja capaz de exercer o papel de artefato na busca da sustentabilidade da qualidade do uso do sistema ERP. Um modelo de auto-regulação que atende a estes requisitos é expresso na figura 1 de forma analítica.

Analisando-se o modelo proposto por Clark et al. (2006) torna-se evidente que o valor alcançado pelo uso do sistema ERP advém não somente do uso integral do aplicativo, mas também pela maneira ou qualidade com a qual este uso é realizado. Este tipo de análise pode ser desenvolvido em dois planos de mensuração: o da organização como um todo, por meio de mecanismos específicos como o modelo proposto por Clark et al. (2006) ou na forma de avaliação individual, atingindo o microcosmo de cada usuário da organização.

Além dos dois patamares de uso do ERP propostos por Clark et al. (2006) (limitado e extensivo), Saga e Zmud (1994) propõem a inclusão de um terceiro patamar de uso dos ERP's denominado "extensivo" no qual os usuários, com base em sua experiência no manejo do aplicativo, passam a explorar novas formas de utilização do ERP, de forma criativa e inovadora, obtendo grande performance operacional em um espaço limitado de tempo. Nestes termos, quanto mais próximo a organização estiver deste patamar, maiores serão os benefícios do uso do ERP, já que os usuários não só utilizarão toda a capacidade da ferramenta, como também a aproveitarão para novas demandas informacionais derivadas do dinamismo do negócio,aproximando-se mais do conceito de sustentabilidade dinâmica citada por Faber, Jorna, Engelen (2005). Baseado nestes argumentos, a qualidade do uso do sistema ERP na fase de pós implementação configura-se como uma importante competência necessária para a aquisição de valor de uso dos sistemas ERP. A figura 2 ilustra de maneira genérica o modelo de auto-regulação.

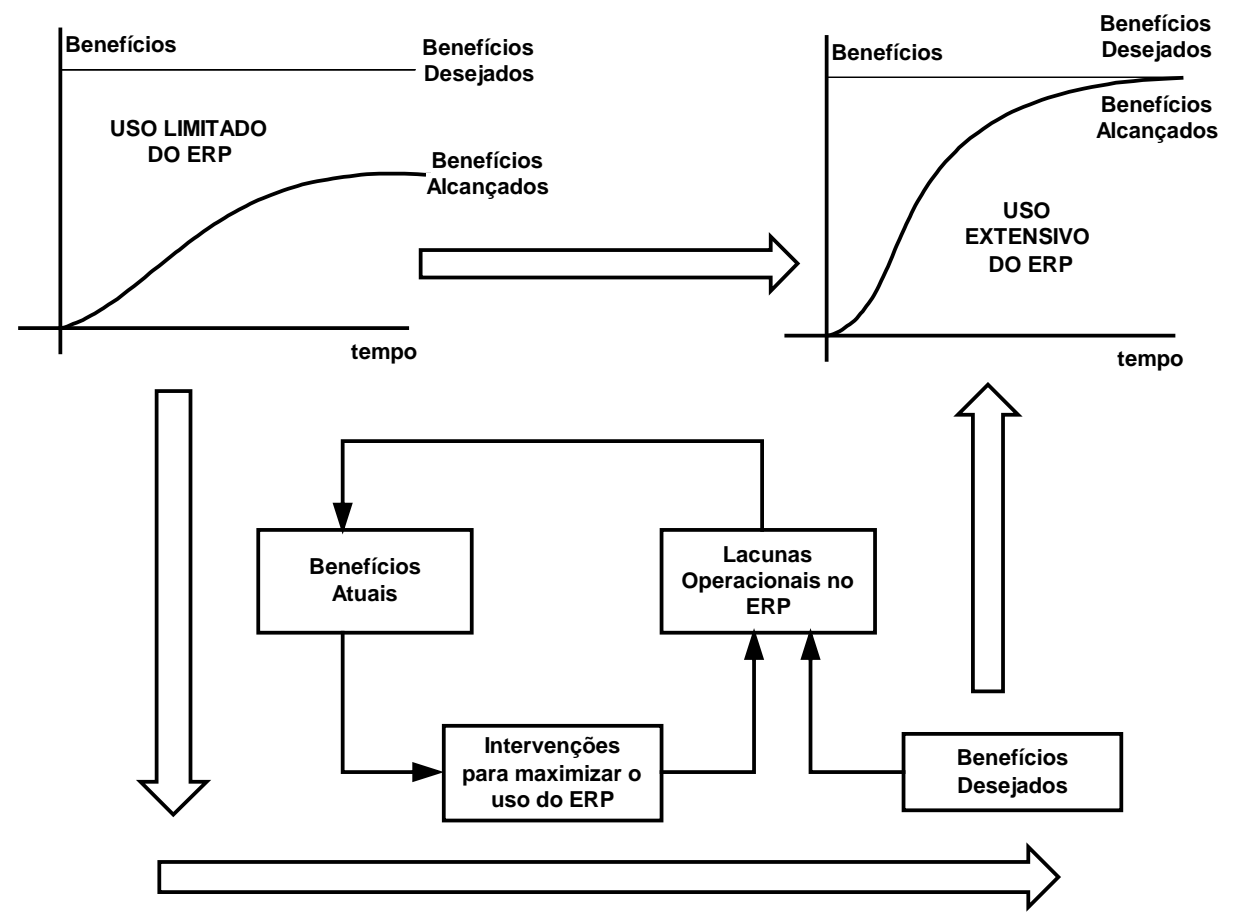

Figura 2 - Diagrama conceitual de auto-regulação em termos da obtenção do valor de uso do ERP. FONTE: Adaptado de Clark et al., 2006, p.4.

Neste contexto, segundo Mata, Fuerst, Barney (1995) a gestão capacitada em TI é a principal e efetiva competência capaz de gerar um diferencial competitivo de forma sustentável. As competências associadas à gestão de TI, de acordo com esta concepção, são: (a) a habilidade dos gestores de TI em compreender as necessidades informacionais do negócio; (b) a habilidade da empresa em conciliar os interesses e integrar as capacidades de gestores, clientes e fornecedores para desenvolver as melhores soluções de $\mathrm{Tl}$; (c) a habilidade de coordenar as atividades de TI de modo a suportar outros gestores internos e demais gestores da cadeia de $\mathrm{TI}$ e (d) a habilidade de antecipar as futuras necessidades dos gestores internos de $\mathrm{TI}$ e demais gestores da cadeia de TI. 
Para Li, Chen, Huang. (2006), as competências organizacionais em TI podem ser classificadas em três dimensões distintas: conhecimento, operações de TI e objetos de TI. Este modelo inclui recursos humanos em TI como um dos atores responsáveis pela estruturação da $\mathrm{Tl}$ em uma organização, pelos seguintes motivos: (a) Pessoas são importantes quando estão implementando sistemas e podem afetar diretamente o seu sucesso ou o seu fracasso; (b) As habilidades da equipe de implantação possuem maior influência sobre os efeitos do projeto e (c) Somente uma equipe competente pode identificar os requerimentos de um projeto complexo.

Nesta mesma linha de raciocínio, coloca Bharadwaj (2000, p.173):

Os recursos humanos em TI incluem as habilidades técnicas e as habilidades gerenciais As habilidades em TI dizem respeito a habilidades como programação, análise e desenho de sistemas e competência em tecnologias nascentes. As habilidades gerenciais incluem habilidades como o gerenciamento efetivo das funções do sistema de informação, coordenação e interação com a comunidade de usuários e habilidades relacionadas a gerenciamento de projeto e liderança.

Como visto, de acordo com a visão de Bharadwaj (2000), as competências organizacionais em TI transcendem o universo específico da competência técnica, sendo constituídas, inclusive, pela capacidade de gerenciamento dos recursos de TI de forma pró-ativa e inovativa, propiciando, assim, condições da organização construir uma vantagem competitiva derivada de seus recursos de $\mathrm{Tl}$ frente aos seus competidores.

Já para Souza e Zwicker (2007, p 4, 5), as competências associadas à gestão da TI estão agrupadas em dois grupos principais, como segue:

No âmbito da gestão da TI, destacam-se dois aspectos: (1) o atendimento das necessidades do negócio, no sentido do alinhamento estratégico da TI com os negócios da empresa e, (2) a resposta tecnológica, no sentido da arquitetura de suporte e portfólio de aplicações. Por outro lado, a gestão da TI envolve decisões de curto prazo (operação de sistemas e processos de TI), de médio prazo (desenvolvimento, implantação e evolução de soluções e plataformas) e de longo prazo (planejamento estratégico de TI), de acordo com parâmetros de custo e de benefício. Starre e Jong (1998) caracterizam estas decisões como decisões sobre o que deve ser feito, designadas como governança da TI, e decisões sobre como deve ser feito, designadas como gerência da TI.

Souza e Zwicker (2007) apresentam um modelo de componentes específicos para a gestão dos ERP's, adaptado a partir das capacidades essenciais de Feeny e Willcocks (1998), de acordo com a ilustração 16. De acordo com Feeny e Willcocks (1998), as capacidades essenciais são:

1) liderança, ou a capacidade de integrar os esforços de TI com os objetivos do negócio; 2) visão sistêmica de negócios, ou a capacidade de vislumbrar os processos que a tecnologia torna possíveis; 3) construção de relacionamentos, ou a capacidade de conseguir o engajamento das áreas usuárias; 4) planejamento da arquitetura, ou a capacidade de criar uma plataforma de tecnologia consistente; 5) fazer a tecnologia funcionar, ou a capacidade de rapidamente resolver problemas inesperados e manter a entrega dos serviços de Tl; 6) aquisição consciente, ou a capacidade de estabelecer e gerenciar a estratégia de fornecimento de serviços, que seja adequada aos negócios; 7) facilitação de contratos, ou a capacidade de gerenciar o dia-a-dia dos contratos de fornecimento de serviços; 8) monitoramento de contratos, ou a capacidade de garantir que a posição atual e futura da empresa seja protegida; e 9) desenvolvimento de fornecedores, ou a capacidade de identificar o potencial para obtenção de valor por meio de TI.

\section{Metodologia da Pesquisa}

A pesquisa empírica realizada neste trabalho pode ser classificada como exploratória, qualitativa, indutiva e foi abordada utilizando-se do método de estudos de casos múltiplos. O estudo de caso é uma pesquisa de caráter empírico que tem por objetivo investigar os fenômenos em seu contexto real. Para alcançar estes objetivos, este tipo de metodologia de pesquisa proporciona a coleta estruturada de informações sobre um ou vários objetos de estudo e pode ser aplicado para descrever, explicar, avaliar e explorar fenômenos contemporâneos que não estão sob o controle do investigador. Para Yin (2005, p.20):

O estudo de caso permite uma investigação para se preservar as características holísticas e significativas dos acontecimentos da vida real - tais como ciclos de vida individuais, processos organizacionais e administrativos, mudanças ocorridas em regiões urbanas, relações internacionais e a maturação de setores econômicos.

De acordo com Martins (2006, p.xi):

No campo das ciências sociais aplicadas há fenômenos de elevada complexidade e de difícil quantificação, como, por exemplo, a supervisão das funções administrativas dentro de uma organização, estratégias de uma organização não governamental, políticas governamentais, etc. Nestes casos, abordagens qualitativas são 
adequadas, tanto no que diz respeito ao tratamento contextual do fenômeno, quanto no que tange à sua operacionalização. O tratamento de eventos complexos pressupõe um maior nível de detalhamento das relações bem como dos relacionamentos que estabelecem com o meio em que estão inseridos.

Neste contexto, o trabalho de campo de uma pesquisa orientada pela estratégia de um estudo de caso é precedido pela exposição do problema de pesquisa e de premissas fundadas em uma teoria preliminar que serão validadas a partir das conclusões da pesquisa (Martins, 2006, p.xii). Nestes termos, com base no levantamento bibliográfico realizado, formulou-se a seguinte premissa de estudo:

- Premissa (PRE): Identificar qual o papel das competências organizacionais com foco na área de TI que sejam direcionadas à plena gestão dos aplicativos ERP's em sua perspectiva de longo prazo. (Mata et al, 1995; Bharadwaj, 2000; Souza e Zwicker, 2007);

Para a elaboração das proposições de pesquisa associados à premissa (PRE), foram utilizados os aspectos relevantes identificados no referencial teórico abaixo relacionado na figura 3:

\begin{tabular}{|l|l|}
\hline Referencial Teórico e Empírico & Aspectos Relevantes \\
\hline $\begin{array}{l}\text { Mata et al. (1995) } \\
\text { Competência dos Gestores em TI }\end{array}$ & $\begin{array}{l}\text { Habilidade dos gestores de TI em compreender as necessidades } \\
\text { informacionais do negócio. }\end{array}$ \\
\hline $\begin{array}{l}\text { Mata et al. (1995) } \\
\text { Alinhamento entre Empresa e } \\
\text { Gestores de TI }\end{array}$ & $\begin{array}{l}\text { Habilidade da empresa em conciliar interesses e integrar as } \\
\text { capacidades de gestores, clientes e fornecedores para desenvolver } \\
\text { as melhores soluções de TI. }\end{array}$ \\
\hline $\begin{array}{l}\text { Mata et al. (1995) } \\
\text { Alinhamento entre Gestores de TI e } \\
\text { demais gestores da empresa }\end{array}$ & $\begin{array}{l}\text { Habilidade de coordenar as atividades de TI de modo a suportar } \\
\text { outros gestores internos e demais gestores da cadeia de TI. }\end{array}$ \\
\hline $\begin{array}{l}\text { Mata et al. (1995) } \\
\text { Capacidade de antecipar necessidades } \\
\text { no âmbito da TI }\end{array}$ & $\begin{array}{l}\text { Habilidade de antecipar as futuras necessidades de TI dos gestores } \\
\text { internos e demais gestores da cadeia de TI. }\end{array}$ \\
\hline $\begin{array}{l}\text { Bharadwaj (2000) } \\
\text { Forte Estrutura em RH - TI }\end{array}$ & $\begin{array}{l}\text { Empresas que possuem um forte posicionamento em termos de } \\
\text { Recursos Humanos de TI estarão habilitadas a integrar os planos de } \\
\text { negócio e de tecnologia de modo mais efetivo. }\end{array}$ \\
\hline $\begin{array}{l}\text { Souza e Zwicker (2007) } \\
\text { Alinhamento da TI com estratégia da } \\
\text { empresa }\end{array}$ & $\begin{array}{l}\text { Atendimento das necessidades do negócio, no sentido do } \\
\text { alinhamento estratégico da TI com os negócios da empresa. }\end{array}$ \\
\hline $\begin{array}{l}\text { Souza e Zwicker (2007) } \\
\text { Resposta Tecnológica [ ERP] }\end{array}$ & $\begin{array}{l}\text { Resposta tecnológica, no sentido da arquitetura de suporte e } \\
\text { portfólio de aplicações. [ ERP]. }\end{array}$ \\
\hline $\begin{array}{l}\text { Souza e Zwicker (2007) } \\
\text { Governança em TI [ ERP] }\end{array}$ & $\begin{array}{l}\text { Sistemas ERP em operação com base em normas de Governança de } \\
\text { TI apresentam maior valor. }\end{array}$ \\
\hline
\end{tabular}

Figura 3 - Competências organizacionais com foco na área de TI: Referencial teórico.

O quadro de referencial teórico expresso na figura 3, a partir do foco da pesquisa pré-determinada pela premissa de estudo, foram estipuladas as seguintes proposições de estudo para serem operacionalizadas (validadas ou refutadas) pela pesquisa de campo, com base em instrumento de pesquisa específico:

- Proposição de pesquisa 1: A área de TI deve alinhar as necessidades informacionais dos gestores de áreas, clientes e fornecedores para proporcionar a construção de melhores processos de negócio e extrair o maior valor dos aplicativos ERP's (Mata et al, 1995; Souza e Zwicker 2007);

- Proposição de pesquisa 2: A TI deve ser composta por profissionais capacitados tanto no aspecto da tecnologia empregada nos ERP's quanto no aspecto do negócio, atuando diretamente nas atividades de suporte e de planejamento junto aos usuários e demais stakeholders vinculados a estes aplicativos (Mata et al, 1995; Bharadwaj, 2000).

Para a operacionalização da pesquisa, foram selecionadas cinco empresas de grande porte, nacionais e multinacionais, todas com faturamento anual acima de 1 bilhão de reais (empresas de amplo conhecimento público) nas áreas de Ensino, Cosméticos, Produtos para a Saúde, Produtos Farmacêuticos e Engenharia. Em cada uma destas empresas foram entrevistados três profissionais que exerciam (no momento das entrevistas) os seguintes cargos: (a) Executivo responsável pela área de $\mathrm{TI}$ (CIO, Diretor de TI, Gerente de TI); (b) Executivo responsável pela área de financeira (CEO, Diretor Financeiro, Controller) e (c) Executivo responsável pela área operacional (Diretor Industrial, Diretor de Vendas, Gerente de Produção), totalizando 15 entrevistados.

Para efeito de escolha das empresas, os critérios fundamentais foram: (a) mesmo patamar de faturamento liquido anual, (b) diversidade da origem do capital, utilização de ERP's de diversos fornecedores (SAP, Oracle, Totvs) e (c) atuação em diferentes segmentos da economia. A diversidade de critérios foi adotada para se minimizar os efeitos das características peculiares de um determinado ERP ou de um determinado segmento de negócio sobre os parâmetros estudados. Adicionalmente, foram seguidos 
rigorosamente todos os procedimentos indicados para a condução de estudos de caso, conforme referenciados por Yin (2005). As unidades de análise consideradas na pesquisa foram as áreas de TI, Financeira e Operacional, de acordo com a natureza de cada empresa participante do estudo. Os nomes das empresas foram mantidos em sigilo a pedido da maioria dos entrevistados.

\section{Resultados da Pesquisa}

Neste tópico, serão apresentados os principais resultados do estudo. Destaca-se a análise cruzada de informações qualitativas colhidas junto aos participantes de cada um dos estudos de caso. Estruturam-se os resultados a partir da evidenciação da proposição de estudo, questão de pesquisa e virtual competência associadas, derivadas da revisão da literatura.

\begin{tabular}{|c|c|}
\hline \multicolumn{2}{|l|}{ Questão de Pesquisa 1} \\
\hline $\begin{array}{l}\text { Proposição de Estudo } \\
\text { (PRO-1) }\end{array}$ & $\begin{array}{l}\text { A área de } T / \text { deve alinhar as necessidades informacionais dos gestores de } \\
\text { áreas, clientes e fornecedores para proporcionar a construção de melhores } \\
\text { processos de negócio e extrair o maior valor dos aplicativos ERP's (Mata et al, } \\
\text { 1995; Souza e Zwicker, 2007) }\end{array}$ \\
\hline $\begin{array}{l}\text { Questão de Pesquisa } \\
\text { (Q1) }\end{array}$ & $\begin{array}{l}\text { Como se dá o processo de coordenação / integração entre a área de Tl e os } \\
\text { gestores de área na identificação de pontos de atenção e de possíveis } \\
\text { melhorias ligados à qualidade da informação oriunda do aplicativo ERP? } \\
\text { Existe um compartilhamento orquestrado de responsabilidades? }\end{array}$ \\
\hline $\begin{array}{l}\text { (Virtual) } \\
\text { Competência } \\
\text { Organizacional (1) }\end{array}$ & $\begin{array}{l}\text { Habilidade da área de Tl em integrar os gestores de áreas usuárias do } \\
\text { aplicativo ERP com a finalidade de compartilhar e homogeneizar os } \\
\text { mecanismos de evolução no sistema. }\end{array}$ \\
\hline
\end{tabular}

Figura 4 - Parâmetros relacionados à análise cruzada referente à questão 1

\subsection{Análise Cruzada das Informações Relacionadas à Questão 1}

Após a análise detalhada das respostas obtidas junto às unidades de análise para a questão 1 é possível chegar a algumas conclusões. A primeira é que, quando foi referenciado o termo “coordenar o processo de integração" a quase totalidade das áreas remeteu esta atividade como sendo de responsabilidade da área de TI. Desta forma, por definição, as áreas financeira e operacional das empresas pesquisadas não descreveram a atividade de gestão do ERP como integrante das suas próprias atribuições, ainda que a integração entre as áreas seja do interesse de todos e não apenas de TI. Por outro lado, de forma unânime, as áreas de $\mathrm{Tl}$ das empresas assumiram totalmente a responsabilidade pela coordenação do processo de integração entre as áreas no ERP, esclarecendo, na maior parte das vezes, que esta atividade está inclusa no dia-a-dia operacional destas áreas. Diante desta polarização entre as áreas de TI e demais áreas analisadas, notou-se uma forte divergência de opiniões relacionada a este assunto. Uma análise bidimensional simplificada associada ao conjunto de respostas colhidas nas empresas em suas respectivas unidades de análise (áreas das empresas) e relacionada à competência organizacional sugerida 1 pode ser analisada na figura 5:

\begin{tabular}{|c|c|c|c|c|}
\hline Competência 1 & $\begin{array}{c}\text { Área: } \\
\text { TI }\end{array}$ & $\begin{array}{c}\text { Área: } \\
\text { Financeira }\end{array}$ & $\begin{array}{c}\text { Área: } \\
\text { Operacional }\end{array}$ & $\begin{array}{c}\text { Convergência } \\
\text { interna entre áreas }\end{array}$ \\
\hline Empresa A & Sim & Não & Não & Tende ao NÃO \\
\hline Empresa B & Sim & Sim & Não & Tende ao SIM \\
\hline Empresa C & Sim & Não & Não & Tende ao NÃO \\
\hline Empresa D & Sim & Não & Não & Tende ao NÃO \\
\hline Empresa E & Sim & Não & Não & Tende ao NÃO \\
\hline $\begin{array}{c}\text { Convergência } \\
\text { entre áreas das } \\
\text { empresas }\end{array}$ & SIM & NÃO & NÃO & $\begin{array}{c}\text { Aderência Geral } \\
\text { SIM: } 40 \% \\
\text { NÃO: } 60 \%\end{array}$ \\
\hline
\end{tabular}

Figura 5 - Aderência entre a competência organizacional virtual 1 e as visões das unidades de análise

\subsection{Análise de Aderência Relacionada à Questão 1}


A habilidade da área de TI em integrar os gestores de áreas usuárias do aplicativo ERP com a finalidade de compartilhar e homogeneizar os mecanismos de evolução no sistema pode ser considerada uma competência organizacional pouco relevante para o processo de sustentação do valor de uso do ERP em seu período de pós implementação. Nota-se que um dos motivos desta pouca relevância associada é o fato desta competência ter sido reconhecida como válida apenas nas áreas de TI, que corroboraram esta visão.

\begin{tabular}{|c|c|}
\hline \multicolumn{2}{|l|}{ Questão de Pesquisa 2} \\
\hline $\begin{array}{l}\text { Proposição de Estudo } \\
\text { (PRO-1) }\end{array}$ & $\begin{array}{l}\text { A área de } T \text { deve alinhar as necessidades informacionais dos gestores de } \\
\text { áreas, clientes e fornecedores para proporcionar a construção de melhores } \\
\text { processos de negócio e extrair o maior valor dos aplicativos ERP's (Mata et al, } \\
1995 ; \text { Souza e Zwicker, 2007) }\end{array}$ \\
\hline $\begin{array}{l}\text { Questão de Pesquisa } \\
\text { (Q2) }\end{array}$ & $\begin{array}{l}\text { Como ocorre o mecanismo de análise das necessidades informacionais } \\
\text { ligadas ao aplicativo ERP pela sua área de forma que as demandas } \\
\text { informacionais em aberto possam ser corrigidas por soluções de caráter } \\
\text { integrador e não de forma pontual?este mecanismo é efetivo? }\end{array}$ \\
\hline $\begin{array}{l}\text { (Virtual) } \\
\text { Competência } \\
\text { Organizacional (2) }\end{array}$ & $\begin{array}{l}\text { Habilidade da área de T/ em coordenar projetos de evolução do aplicativo ERP } \\
\text { baseado em projetos estruturados capazes de abarcar soluçóes } \\
\text { compartilhadas a pontos de melhoria requisitados por diversas áreas usuárias } \\
\text { do sistema }\end{array}$ \\
\hline
\end{tabular}

Figura 6 - Parâmetros relacionados à análise cruzada referente à questão 2

\subsection{Análise Cruzada das Informações Relacionadas à Questão 2}

Após realizar a análise das respostas obtidas para a questão 2, é possível realizar algumas inferências. A primeira diz respeito, novamente, ao fato de que o aspecto de integração de ações no ERP entre áreas foi refutada pela quase totalidade das unidades de análise financeira e operacional. Para estas áreas, em sua grande maioria, a responsabilidade de alinhar as necessidades informacionais dos gestores de áreas, clientes e fornecedores para proporcionar a construção dos melhores processos de negócio e extrair o maior valor dos aplicativos ERP's é de responsabilidade da área de TI. Neste aspecto, as repostas colhidas em campo convergem para o fato de que o ERP, sob a coordenação da TI é, de fato, o responsável pela integração existente entre as áreas de uma mesma empresa, já que devido à sua utilização as áreas se interessam pela qualidade dados que advém de outras áreas. A análise bidimensional associada ao conjunto de respostas colhidas nas empresas em suas respectivas unidades de análise e relacionada à competência organizacional sugerida 2 pode ser analisada na figura 7:

\begin{tabular}{|c|c|c|c|c|}
\hline Competência 2 & $\begin{array}{c}\text { Área: } \\
\text { TI }\end{array}$ & $\begin{array}{c}\text { Área: } \\
\text { Financeira }\end{array}$ & $\begin{array}{c}\text { Área: } \\
\text { Operacional }\end{array}$ & $\begin{array}{c}\text { Convergência } \\
\text { interna entre áreas }\end{array}$ \\
\hline Empresa A & Sim & Não & Não & Tende ao NÃO \\
\hline Empresa B & Sim & Sim & Não & Tende ao SIM \\
\hline Empresa C & Sim & Não & Sim & Tende ao NÃO \\
\hline Empresa D & Sim & Não & Não & Tende ao NÃO \\
\hline Empresa E & Sim & Não & Não & Tende ao NÃO \\
\hline $\begin{array}{c}\text { Convergência } \\
\text { entre áreas das } \\
\text { empresas }\end{array}$ & SIM & NÃO & NÃO & $\begin{array}{c}\text { Aderência Geral } \\
\text { SIM: } 47 \% \\
\text { NÃO: } 53 \%\end{array}$ \\
\hline
\end{tabular}

Figura 7 - Aderência entre a competência organizacional virtual 2 e as visões das unidades de análise

\subsection{Análise de Aderência Relacionada à Questão 2}

A habilidade da área de TI em coordenar projetos de evolução do aplicativo ERP baseado em projetos estruturados capazes de abarcar soluções compartilhadas a pontos de melhoria requisitados por diversas áreas usuárias do sistema pode ser considerada uma competência organizacional pouco relevante para o processo de sustentação do valor de uso do ERP em seu período de pós implementação. Da mesma forma que o item anterior, esta competência não está distribuída de maneira uniforme entre as áreas pesquisadas, o que faz com que a área de TI seja a responsável por estruturar tais competências com base em seus próprios recursos. 


\begin{tabular}{|c|l|}
\hline \multicolumn{2}{|l|}{ Questão de Pesquisa 3} \\
\hline $\begin{array}{c}\text { Proposição de Estudo } \\
\text { (PRO-1) }\end{array}$ & $\begin{array}{l}\text { A área de Tl deve alinhar as necessidades informacionais dos gestores de } \\
\text { reas, dientes e fornecedores para proporcionar a construção de melhores } \\
\text { processos de negócio extrair o maior valor dos aplicativos ERP's (Mata et al, } \\
1995 ; \text { Souza e Zwicker, 2007) }\end{array}$ \\
\hline Questão de Pesquisa & $\begin{array}{l}\text { Como ocorre a gestão de conflitos envolvendo demandas informacionais } \\
\text { típicas do aplicativo ERP junto às demais áreas ou agentes externos à } \\
\text { organização? Existe uma política universal de atendimento a demandas } \\
\text { informacionais no ERP previamente estabelecida e conhecida por todos? }\end{array}$ \\
\hline $\begin{array}{c}\text { Competência } \\
\text { Organizacional (3) }\end{array}$ & $\begin{array}{l}\text { Capacidade da área de Tl em desenvolver, implementar e compartilhar com } \\
\text { todas as áreas usuárias do aplicativo ERP um plano de gestão único para este } \\
\text { sistema integrador, de forma a orientar as melhores práticas e ordenar as } \\
\text { demandas de melhorias em curso. }\end{array}$ \\
\hline
\end{tabular}

Figura 8 - Parâmetros relacionados à análise cruzada referente à questão 3

\subsection{Análise Cruzada das Informações Relacionadas à Questão 3}

A leitura das respostas colhidas relacionadas à questão 3 viabiliza a construção de duas evidências principais. A primeira, e mais evidente, é a de que a maioria absoluta das unidades de análise estudadas compreende que a capacidade de priorização de investimentos no âmbito do ERP é fundamental para que cada uma das áreas envolvidas procure realizar sua própria análise de custo-benefício envolvendo customizações. A segunda conclusão diz respeito às áreas de TI que, assim como nas questões anteriores relacionadas à proposição 04, demonstraram total aderência à essência da questão, que trata da existência ou não de mecanismos de criação de políticas para a gestão do ERP em função de demandas distintas advindas de áreas diversas. Nota-se pelo conjunto de respostas que a área de TI das empresas suporta com tranqüilidade o estabelecimento das competências necessárias para dar vazão a estes mecanismos de gestão de budget e de expectativas das áreas envolvidas. A análise bidimensional associada ao conjunto de respostas colhidas nas empresas em suas respectivas unidades de análise pode ser analisada na figura 9:

\begin{tabular}{|c|c|c|c|c|}
\hline Competência 3 & $\begin{array}{c}\text { Área: } \\
\text { TI }\end{array}$ & $\begin{array}{c}\text { Área: } \\
\text { Financeira }\end{array}$ & $\begin{array}{c}\text { Área: } \\
\text { Operacional }\end{array}$ & $\begin{array}{c}\text { Convergência } \\
\text { interna entre áreas }\end{array}$ \\
\hline Empresa A & Sim & Sim & Não & Tende ao SIM \\
\hline Empresa B & Sim & Sim & Não & Tende ao SIM \\
\hline Empresa C & Sim & Sim & Sim & SIM \\
\hline Empresa D & Sim & Sim & Não & Tende ao SIM \\
\hline Empresa E & Sim & Sim & Sim & SIM \\
\hline $\begin{array}{c}\text { Convergência } \\
\text { entre áreas das } \\
\text { empresas }\end{array}$ & SIM & SIM & SIM & $\begin{array}{c}\text { Aderência Geral } \\
\text { SIM: } 80 \% \\
\text { NÃO: } 20 \%\end{array}$ \\
\hline
\end{tabular}

Figura 9 - Aderência entre a competência organizacional virtual 3 e as visões das unidades de análise

\subsection{Análise de Aderência Relacionada à Questão 3}

A capacidade da área de TI em desenvolver, implementar e compartilhar com todas as áreas usuárias do aplicativo ERP um plano de gestão único para este sistema integrador, de forma a orientar as melhores práticas e ordenar as demandas de melhorias em curso é, de fato, uma competência organizacional de muita relevância para o processo de sustentação do valor de uso do ERP em seu período de pós implementação, na medida em que gera um mecanismo de equilíbrio entre todas as áreas usuárias do ERP.

\begin{tabular}{|c|l|}
\hline Questão de Pesquisa 4 & $\begin{array}{l}\text { A área de TI deve ser composta por profissionais capacitados } \\
\text { simultaneamente tanto no aspecto da tecnologia empregada nos ERP's } \\
\text { quanto no aspecto do negócio, atuando diretamente nas atividades de } \\
\text { suporte e de planejamento junto aos usuários e demais stakeholders } \\
\text { vinculados a estes aplicativos (Mata et al, 1995; Bharadwaj, 2000) }\end{array}$ \\
\hline
\end{tabular}

Figura 10 - Parâmetros relacionados à análise cruzada referente à questão $4 \quad$ (Continua...) 


\begin{tabular}{|c|l|}
\hline $\begin{array}{c}\text { Questão de Pesquisa } \\
\text { (Q4) }\end{array}$ & $\begin{array}{l}\text { Como a sua área determina o perfil dos profissionais que irão desempenhar o } \\
\text { papel de usuário do aplicativo ERP ? Existem atividades de suporte corretivo } \\
\text { junto aos demais usuários do aplicativo ERP por parte de TI? }\end{array}$ \\
\hline $\begin{array}{c}\text { (Virtual) } \\
\text { Competência }\end{array}$ & $\begin{array}{l}\text { Habilidade da área de Tl em selecionar profissionais com competência técnica } \\
\text { para atuar nas atividades de suporte corretivo às operaçóes correntes do } \\
\text { aplicativo ERP cujo perfil seja aderente à necessidade de profundo } \\
\text { conhecimento dos processos de negócio da empresa aliado à certificação } \\
\text { profissional necessária para desempenhar este tipo de função. }\end{array}$ \\
\hline
\end{tabular}

(Continuação...) Figura 10 - Parâmetros relacionados à análise cruzada referente à questão 4

\subsection{Análise Cruzada das Informações Relacionadas à Questão 4}

Após a análise das respostas relacionadas à questão 4 é possível concluir que de forma unânime, a questão da competência necessária para estabelecer uma equipe adequada de consultores dedicados ao suporte corretivo pode ser considerada de grande relevância. Ainda que parte dos entrevistados tenha declarado que a competência de estabelecer a equipe de suporte caiba à área de TI, de uma forma geral todos os entrevistados citaram livremente a ausência de problemas mais significativos com o ERP derivados deste tipo de suporte. Uma análise bidimensional simplificada associada ao conjunto de respostas colhidas nas empresas em suas respectivas unidades de análise (áreas das empresas) e relacionada à competência organizacional sugerida 4 pode ser analisada na figura 11:

\begin{tabular}{|c|c|c|c|c|c|}
\hline Competência 4 & $\begin{array}{c}\text { Área: } \\
\text { TI }\end{array}$ & $\begin{array}{c}\text { Área: } \\
\text { Financeira }\end{array}$ & $\begin{array}{c}\text { Área: } \\
\text { Operacional }\end{array}$ & $\begin{array}{c}\text { Convergência } \\
\text { interna entre áreas }\end{array}$ \\
\hline Empresa A & Sim & Sim & Sim & SIM \\
\hline Empresa B & Sim & Sim & Sim & SIM \\
\hline Empresa C & Sim & Sim & Sim & SIM \\
\hline Empresa D & Sim & Sim & Sim & SIM \\
\hline Empresa E & Sim & Sim & Sim & \\
\hline $\begin{array}{c}\text { Convergência } \\
\text { entre áreas das } \\
\text { empresas }\end{array}$ & SIM & SIM & SIM & $\begin{array}{c}\text { Aderência Geral } \\
\text { SIM: } 100 \% \\
\text { NÃO: } 0 \%\end{array}$ \\
\hline
\end{tabular}

Figura 11 - Aderência entre a competência organizacional virtual 4 e as visões das unidades de análise

\subsection{Análise de Aderência Relacionada à Questão 4}

A habilidade da área de TI em selecionar profissionais com competência técnica para atuar nas atividades de suporte corretivo às operações correntes do aplicativo ERP cujo perfil seja aderente à necessidade de profundo conhecimento dos processos de negócio da empresa aliado à certificação profissional necessária para desempenhar este tipo de função pode ser considerada uma competência organizacional de extrema relevância para o processo de sustentação do valor de uso do ERP em seu período de pós implementação, na medida em que tal competência foi reconhecida de forma espontânea por todos os entrevistados, pertencentes às três vertentes de unidades de análise consultadas.

\begin{tabular}{|c|l|}
\hline Questão de Pesquisa 5 & $\begin{array}{l}\text { A área de TI deve ser composta por profissionais capacitados } \\
\text { simultaneamente tanto no aspecto da tecnologia empregada nos ERP's } \\
\text { quanto no aspecto do negócio, atuando diretamente nas atividades de } \\
\text { suporte e de planejamento junto aos usuários e demais stakeholders } \\
\text { vinculados a estes aplicativos (Mata et al, 1995; Bharadwaj, 2000) }\end{array}$ \\
\hline $\begin{array}{c}\text { (PRO-2) } \\
\text { Questão de Pesquisa } \\
\text { (Q5) }\end{array}$ & $\begin{array}{l}\text { Como a área de T/ determina o perfil dos profissionais que irão desempenhar } \\
\text { atividades de suporte corretivo e evolutivo junto aos usuários do aplicativo } \\
\text { ERP em sua área organizacional?Estes perfis são factiveis? }\end{array}$ \\
\hline (Virtual) & $\begin{array}{l}\text { Habilidade da área de TI em selecionar profissionais com competência de } \\
\text { caráter funcional para atuar nas atividades de suporte evolutivo às operaçóes } \\
\text { correntes do aplicativo ERP cujo perfil seja aderente à necessidade de } \\
\text { profundo conhecimento dos processos de negócio da empresa aliado à } \\
\text { certificação profissional necessária para desempenhar este tipo de função. }\end{array}$ \\
\hline Organizacional (5)
\end{tabular}

Figura 12 - Parâmetros relacionados à análise cruzada referente à questão 5 


\subsection{Análise Cruzada das Informações Relacionadas à Questão 5}

Após a análise das respostas relacionadas à questão 5 é possível concluir que de forma unânime, a questão da competência necessária para estabelecer uma equipe adequada de consultores dedicados ao suporte evolutivo pode ser considerada de grande relevância. Ainda que parte dos entrevistados tenha declarado que a competência de estabelecer a equipe de desenvolvimento caiba à área de TI, de uma forma geral todos os entrevistados citaram de forma espontânea a ausência de problemas mais significativos com o ERP derivados deste tipo de atividade. Uma análise bidimensional simplificada associada ao conjunto de respostas colhidas nas empresas em suas respectivas unidades de análise (áreas das empresas) e relacionada à competência organizacional sugerida 5 pode ser analisada na figura 13:

\begin{tabular}{|c|c|c|c|c|}
\hline Competência 5 & $\begin{array}{c}\text { Área: } \\
\text { TI }\end{array}$ & $\begin{array}{c}\text { Área: } \\
\text { Financeira }\end{array}$ & $\begin{array}{c}\text { Área: } \\
\text { Operacional }\end{array}$ & $\begin{array}{c}\text { Convergência } \\
\text { interna entre áreas }\end{array}$ \\
\hline Empresa A & Sim & Sim & Sim & SIM \\
\hline Empresa B & Sim & Sim & Sim & SIM \\
\hline Empresa C & Sim & Sim & Sim & SIM \\
\hline Empresa D & Sim & Sim & Sim & SIM \\
\hline Empresa E & Sim & Sim & Sim & Aderência Geral \\
SIM: 100\% \\
NÂO: $0 \%$
\end{tabular}

Figura 13 - Aderência entre a competência organizacional virtual 5 e as visões das unidades de análise

\subsection{Análise de Aderência Relacionada à Questão 5}

A habilidade da área de TI em selecionar profissionais com competência técnica para atuar nas atividades de desenvolvimento de melhorias do aplicativo ERP cujo perfil seja aderente à necessidade de profundo conhecimento dos processos de negócio da empresa aliado à certificação profissional necessária para desempenhar este tipo de função pode ser considerada uma competência organizacional de extrema relevância para o processo de sustentação do valor de uso do ERP em seu período de pós implementação, na medida em que tal competência foi reconhecida de forma espontânea por todos os entrevistados, pertencentes às três vertentes de unidades de análise consultadas.

\begin{tabular}{|c|c|}
\hline \multicolumn{2}{|l|}{ Questão de Pesquisa 6} \\
\hline $\begin{array}{l}\text { Proposição de Estudo } \\
\text { (PRO-2) }\end{array}$ & $\begin{array}{l}\text { A área de TI deve ser composta por profissionais capacitados } \\
\text { simultaneamente tanto no aspecto da tecnologia empregada nos ERP's } \\
\text { quanto no aspecto do negócio, atuando diretamente nas atividades de } \\
\text { suporte e de planejamento junto aos usuários e demais stakeholders } \\
\text { vinculados a estes aplicativos (Mata et al, } 1995 ; \text { Bharadwaj, 2000) }\end{array}$ \\
\hline $\begin{array}{l}\text { Questão de Pesquisa } \\
(\mathrm{Q} 6)\end{array}$ & $\begin{array}{l}\text { Como a área de TI estrutura sua logística de atendimento aos usuários do } \\
\text { aplicativo ERP pertencentes à sua área de negócio?Este sistema é eficaz? }\end{array}$ \\
\hline $\begin{array}{l}\text { (Virtual) } \\
\text { Competência } \\
\text { Organizacional (6) }\end{array}$ & $\begin{array}{l}\text { Capacidade da área de Tl em atuar de forma integrada às áreas de negócio } \\
\text { da empresa, criando condiçóes propícias e otimizadas para suportar a } \\
\text { operação do aplicativo ERP. }\end{array}$ \\
\hline
\end{tabular}

Figura 14 - Parâmetros relacionados à análise cruzada referente à questão 6

\subsection{Análise Cruzada das Informações Relacionadas à Questão 6}

Após a análise das respostas associadas à questão 6, é possível concluir que a questão da estruturação da logística associada às atividades de suporte e de desenvolvimento de melhorias no âmbito do ERP foi reconhecida como relevante por todas as áreas pesquisadas, de forma homogênea. Tal constatação, ainda que cada empresa possua seu próprio modelo de infraestrutura relacionada, deriva do fato que o aplicativo ERP requer uma articulação constante em termos de suporte especializado, para que continue a operar em condições de gerar valor de uso. Uma análise bidimensional simplificada associada ao conjunto de respostas colhidas nas empresas em suas respectivas unidades de análise (áreas das empresas) e relacionada à competência organizacional sugerida 6 pode ser analisada na figura 15 : 
A gestão de ti e o valor de uso dos ERP's em sua perspectiva de pós implementação

\begin{tabular}{|c|c|c|c|c|}
\hline Competência 6 & $\begin{array}{c}\text { Área: } \\
\text { TI }\end{array}$ & $\begin{array}{c}\text { Área: } \\
\text { Financeira }\end{array}$ & $\begin{array}{c}\text { Área: } \\
\text { Operacional }\end{array}$ & $\begin{array}{c}\text { Convergência } \\
\text { interna entre áreas }\end{array}$ \\
\hline Empresa A & Sim & Sim & Sim & SIM \\
\hline Empresa B & Sim & Sim & Sim & SIM \\
\hline Empresa C & Sim & Sim & Sim & SIM \\
\hline Empresa D & Sim & Sim & Sim & SIM \\
\hline Empresa E & Sim & Sim & Sim & SIM \\
\hline $\begin{array}{c}\text { Convergência } \\
\text { entre áreas das } \\
\text { empresas }\end{array}$ & SIM & SIM & SIM & $\begin{array}{l}\text { Aderência Geral } \\
\text { SIM: } 100 \% \\
\text { NÃO: } 0 \%\end{array}$ \\
\hline
\end{tabular}

Figura 15 - Aderência entre a competência organizacional virtual 6 e as visões das unidades de análise

\subsection{Análise de Aderência Relacionada à Questão 6}

A capacidade da área de TI em atuar de forma integrada às áreas de negócio da empresa, criando condições propícias e otimizadas para suportar a operação do aplicativo ERP é, de fato, uma competência organizacional extremamente relevante para o processo de sustentação do valor de uso do ERP em seu período de pós implementação, já que este tipo de aplicativo requer medidas constantes de caráter corretivo e também adaptativo.

\section{Conclusões}

O papel das competências organizacionais da área de TI vinculadas ao processo de sustentação do valor de uso do ERP é de relevância acentuada, proporciona forte impacto nas rotinas de administração interna destes aplicativos e são essenciais para que as empresas mantenham-se em equilíbrio operacional e em condições de construírem bases informacionais robustas para efeito de gestão interna e de reporte legal ao governo.

A conclusão final desta pesquisa contém seus elementos constituintes na forma de conclusões adjuntas que, reunidas, permitiram a sua constituição. As conclusões fomentadoras desta afirmação expressa de forma conclusiva partiram de dimensões de análise relevantes e complementares, conforme se evidenciou ao longo do estudo. As dimensões de análise são apresentadas a seguir e formam a base conclusiva desta pesquisa.

De acordo com o expresso nas análises de aderência anteriores, conclui-se que a proposição de estudo 1, de que a área de TI deve ser a responsável pelo alinhamento das necessidades informacionais dos gestores de áreas, clientes e fornecedores para proporcionar a construção dos melhores processos de negócio e extrair o maior valor dos aplicativos ERP's pode ser analisado por quatro grandes vertentes.

A primeira vertente evidencia que, em termos de análises efetuadas sobre as áreas de uma mesma empresa, existe um desalinhamento considerável entre as áreas de Tl, financeira e operacional, nesta ordem, envolvendo a temática da proposição de estudo 1. Tal constatação deriva do fato que a necessidade de alinhamento informacional entre as áreas para uma melhor gestão de processos do ERP que os operacionaliza necessita, claramente, de um conjunto de competências organizacionais que estão concentradas na área de TI, ainda que todas as áreas usuárias de ERP necessitem organizar-se e comunicar-se mutuamente.

A segunda vertente de análise permite inferir que a área de Tl das empresas, com a unanimidade das observações efetuadas, é extremamente aderente às competências organizacionais propostas no tocante à administração das necessidades informacionais das áreas usuárias do ERP para proporcionar a construção dos melhores processos de negócio. Nota-se que as áreas de TI das empresas possuem um entendimento muito semelhante, para não dizer repetitivo, acerca de sua responsabilidade inata relacionada à coordenação e à priorização das atividades de melhorias no âmbito dos aplicativos ERP's.

A terceira vertente de análise está associada à área de finanças frente à quarta proposição da pesquisa. Como se pôde notar, em geral a área financeira responde aos desafios citados colocando-se no papel de área dependente de TI tanto para executar algum tipo de coordenação do processo de interação entre os gestores de áreas relacionadas ao aplicativo ERP como também para analisar demandas informacionais em aberto que possam ser corrigidas por soluções de caráter integrador. Nota-se, contudo, que as áreas 
financeiras das empresas participam com tranqüilidade do processo de gestão das demandas por melhorias nos aplicativos ERP em sua maioria conduzida pela área de TI.

A quarta vertente de análise está restrita à área operacional. De acordo com as observações efetuadas nota-se que em sua quase totalidade, as unidades de análise operacionais refutam-se a desenvolver competências que possam relacionar-se às tarefas de coordenação ou de análise que possam inseri-las em um contexto mais privilegiado em termos do universo dos ERP's. Ainda que algumas áreas operacionais tenham sinalizado positivamente com relação ao compartilhamento de ações visando coordenar ações de natureza integradora, a maioria das áreas operacionais identificou-se como não aderente ao compartilhamento de esforços neste sentido.

De igual forma, de acordo com o expresso nas análises de aderência anteriores, conclui-se que a proposição de estudo 2, de que a área de TI deve ser composta por profissionais capacitados simultaneamente tanto no aspecto da tecnologia empregada nos ERP's quanto no aspecto do negócio, atuando diretamente nas atividades de suporte e de planejamento junto aos usuários e demais stakeholders pode ser analisado por três grandes vertentes.

A primeira vertente evidencia que, em termos de análises efetuadas sobre as áreas de uma mesma empresa, existe como regra geral a percepção de alinhamento entre as áreas de TI, financeira e operacional, envolvendo a temática da segunda proposição de pesquisa. Como observado, todas as áreas das empresas corroboram a visão de que o ERP deve ser suportado por profissionais habilitados e certificados, seja na modalidade de equipe própria, seja na modalidade de outsourcing. Da mesma forma, é de compreensão geral entre as áreas que deve haver uma estrutura de atendimento que dê vazão às demandas corretivas e adaptativas envolvendo pontualmente os profissionais das áreas usuárias do ERP, a fim de testarem e validarem ações de melhorias desenvolvidas.

A segunda vertente de análise permite inferir que a área de TI das empresas, com a unanimidade das observações efetuadas, é extremamente aderente às competências organizacionais propostas no tocante à administração dos recursos e da logística empregados no suporte do aplicativo ERP. Tal constatação veio acompanhada dos comentários dos responsáveis pelas áreas de $\mathrm{TI}$, nos quais se percebe a tendência em estabelecer parâmetros bem delineados com relação ao atendimento de suporte às atividades correntes dos ERP's.

A terceira vertente de análise está associada às áreas financeiras e operacionais frente à segunda proposição da pesquisa. Nota-se que em geral estas áreas sentem-se amparadas pelas áreas de TI, à qual atribuem a responsabilidade pela formação e manutenção das equipes e da infraestrutura de atendimento para as demandas corretivas e adaptativas. Nota-se que, apesar deste descolamento no sentido de reconhecimento de responsabilidades, estas áreas sentem-se confortáveis para tratar do tema, evidenciando certa "intimidade operacional" vinculada às competências desenvolvidas pela área de TI associadas à proposição de pesquisa.

De acordo com o que pôde ser observado nas análises preliminares relacionadas às proposições de estudo 1 e 2, de fato existe um conjunto de competências organizacionais que estão associadas às área de TI e a maneira pela qual as mesmas conduzem a gestão dos aplicativos ERP's. Este fato já era esperado devido estarem expressos na literatura os direcionadores teóricos que orientaram a formulação das proposições de estudo relacionadas à premissa do estudo, bem como as questões de pesquisa associadas.

Desta forma e como observado anteriormente, foi possível propor um conjunto de seis competências organizacionais associadas às proposições de estudo que, após terem sido analisadas individualmente, permitiu com que o papel de cada uma delas fosse associado a uma escala relativa de significância para as áreas das empresas analisadas. Uma vez que as unidades de análise desta pesquisa puderam ser analisadas em conjunto, este fato permitiu constituir um parâmetro para o estabelecimento de uma análise estendida destas mesmas competências organizacionais, relacionando-as a cada empresa como um todo. Desta forma, as competências organizacionais propostas associadas às melhores avaliações por parte dos entrevistados devem ser constantemente aprimoradas pelas organizações usuárias dos aplicativos ERP's.

\section{Referências}

Bharadwaj, A. S. (2000). A resource-based perspective on information technology capability and firm performance: an empirical investigation. MIS Q., 24(1), 169-196. doi: 10.2307/3250983. 
Boudreau, M.-C. (2003). Learning to Use ERP Technology: A Causal Model. Paper presented at the Proceedings of the 36th Annual Hawaii International Conference on System Sciences (HICSS'03) - Track 8 Volume 8.

Clark, T. D., Jones M. C., Zmud, R.W. (2006). Post Adoptive ERP Use Behaviors: A Dynamic Conceptualization. [S.I]: Working Paper.[S.I]: 2-2, February 17, 2006.

Davenport, T. H. (2002). Missão crítica: obtendo vantagem competitiva com os sistemas de gestão empresarial. Porto Alegre: Bookman.

Faber, N., Jorna, R., \& Engelen, J. V. (2005). The Sustainability Of "Sustainability": A Study Into The Conceptual Foundations Of The Notion Of "Sustainability". Journal of Environmental Assessment Policy and Management (JEAPM), 7(01), 1-33. http://dx.doi.org/10.1142/S1464333205001955

Feeny, D. e Willcocks, L. (1998) Core IS capabilities for exploiting IT. Sloan Management Review, 39, 3, 921.

Laurindo, F. J. B. (2006). Gestão integrada de Processos e da tecnologia da informação. São Paulo: Atlas.

Li, E.Y., Chen, J. S., Huang, Y.H. (2006). A framework for investigating the impact of IT capability and organizational capability on firm performance in the late industrializing context. International fournal of Technology Management, 36(1/2/3), 209-229.

Martins, G. A. (2006) Estudo de Caso: Uma Estratégia de Pesquisa. São Paulo, Atlas.

Mata, F. J., Fuerst, W. L., \& Barney, J. B. (1995). Information technology and sustained competitive advantage: a resource-based analysis. MIS Q., 19(4), 487-505. doi: 10.2307/249630.

Mizik, N., \& Jacobson, R. (2003). Trading off between Value Creation and Value Appropriation: The Financial Implications of Shifts in Strategic Emphasis. /Mark, 67(1), 63-76. doi: 10.2307/30040511.

Saga, V. L., \& Zmud, R. W. (1994). The Nature and Determinants of IT Acceptance, Routinization, and Infusion. Paper presented at the Proceedings of the IFIP TC8 Working Conference on Diffusion, Transfer and Implementation of Information Technology.

Souza, C. A. d., \& Zwicker, R. (2007). Capacidades e atores na gestão de sistemas ERP: um estudo exploratório entre usuários corporativos do ERP da SAP. JISTEM - Journal of Information Systems and Technology Management (Online), 4, 197-215.

Starre, D., \& Jong, B. (1998). IT governance and management. Nolan Norton Institute research memorandum, June.

Umble, E. J., Haft, R. R., \& Umble, M. M. (2003). Enterprise resource planning: Implementation procedures and critical success factors. European journal of Operational Research, 146(2), 241-257.

Yin, R. K. (2005). Estudo de Caso: Planejamento e Métodos (Vol. 3). Porto Alegre: Bookman. 